\title{
TEMPERATURE INTER-COMPARISON EFFORT IN THE FRAMEWORK OF HYDROLOGICAL CYCLE IN THE MEDITERRANEAN EXPERIMENT - SPECIAL ObSERVATION PERIOD (HYMEX-SOP1)
}

\author{
Benedetto De Rosa ${ }^{1}$, Paolo Di Girolamo ${ }^{1}$, Donato Summa ${ }^{1}$, Cyrille Flamant ${ }^{2}$, Olivier Bousquet ${ }^{3}$, \\ Marco Cacciani ${ }^{4}$, Dario Stelitano ${ }^{1}$ \\ [1] Scuola di Ingegneria, Università degli Studi della Basilicata, \\ 85100 Potenza-Italy, emails: benedetto.derosa@unibas.it; \\ digirolamo@unibas.it;donato.summa@unibas.it \\ [2] LATMOS/IPSL, UPMC Univ. Paris 06 Sorbonne Universités, UVSQ, CNRS, Paris, France, email: \\ cyrille.flamant@latmos.ipsl.fr \\ [3] Météo-France \& Laboratoire de l'Atmosphère et des Cyclones, DIROI / CRC, \\ 97490 Sainte Clotilde Cedex, France, email: olivier.bousquet@meteo.fr \\ [4] Dipartimento di Fisica, Università di Roma "La Sapienza", Piazzale Aldo Moro, n. 2, \\ 00100 Roma-Italy,email:marco.cacciani@uniromal.it
}

\begin{abstract}
Accurate measurements of the vertical profiles of atmospheric temperature are necessary to advance the knowledge of dynamics-thermodynamicsradiative interaction mechanisms triggering convection, and ultimately improve weather forecasting capabilities. Comprehensive intercomparisons between different remote sensing and in-situ sensors have to be carried for the purpose of obtaining accurate error estimates for these sensors. This paper reports results obtained in the frame of the Hydrological Cycle in the Mediterranean Experiment - Special Observation Period (HyMeX-SOP1).
\end{abstract}

\section{INTRODUCTION}

The Hydrological Cycle in the Mediterranean Experiment aims at a better understanding, of the hydrological cycle in the Mediterranean, with specific emphasis on the observation and modeling of extreme weather events.

Heavy precipitation and flash-flooding events affect the Mediterranean coastline as a consequence of specific forcing mechanisms (orography) and abundant evaporation from the sea surface. These events, which may cause hundreds of millions of euros in damages, are usually associated with increasing levels of humidity within the boundary layer and the lower part of the free troposphere The role that played by water vapour on meteorological process is only partially understood due to its highly variable distribution in space and time. This characteristic is partially determined by the fact that water vapour pressure varies significantly with temperature. Therefore accurate and high spacetemporal resolution measurements of the vertical profiles temperature are even more necessary in these areas. A proper understanding addressing of these

The improvement of weather forecasting skills, especially in the presence of extreme events, requires an appropriate comprehension of the key processes influenced by the three-dimensional distribution of atmospheric water vapor and temperature. As a consequence, accurate and high-resolution global-scale measurements of the vertical profiles of atmospheric temperature, besides those of water vapour mixing ratio, are highly necessary. Unfortunately, none of the presently available measurement techniques for tropospheric temperature profiling is able to achieve the highly demanding observational requirements, in terms of measurement accuracy and precision, capable to produce a significant impact on mesoscale weather prediction. Some observational networks, such as the network of upper air radiosounding stations, are characterized by a sufficient density of sensors, high accuracy and vertical resolution, but lack in temporal resolution. Other networks, on the other hand, such as the global network of ground-based microwave radiometers, are characterized by a sufficient density of sensors, high accuracy and temporal resolution, but lack in vertical resolution. 
These limitations can be in principle overcome based on the implementation of a network of lidar systems exploiting the rotational Raman technique.

In this paper, we report results from an intercomparison study involving a temperature Raman lidar and other in-situ and remote sensing sensors with the purpose of obtaining accurate error estimates for all the involved instruments. More specifically, Raman lidar temperature profiles are compared to those collected by an in-situ temperature sensor deployed on-board the French research aircraft ATR42, operated by the Service des Avions Instrumentés pour la Recherche en Environnement (SAFIRE), as well as to those collected by a microwave radiometer and radiosondes.

Measurements reported in this paper were carried out in the frame of HyMeX-SOP1. Within this experiment a major field campaign, SOP1, took place in the period September-November 2012 over the northwestern Mediterranean Sea and its surrounding coastal regions in France, Italy and Spain. In the frame of HyMeX-SOP1, the University of BASILicata ground-based Raman Lidar system (BASIL) was deployed in the Cévennes-Vivarais site (Candillargues, Southern France, Lat: $43^{\circ} 37^{\prime} \mathrm{N}$, Long: $4^{\circ} 4^{\prime} \mathrm{E}$, Elev: $1 \mathrm{~m}$ ) and operated from 5 September to 5 November 2012.The inter-comparison effort described in this work allows obtaining accurate error estimates for the involved sensors. For this purpose, simultaneous and co-located profiles from different sensors' pairs are considered. These are used to compute the mutual BIAS and root-meansquare (RMS) deviation between the different sensors' pairs as a function of height. Similar sensors' intercomparison studies involving lidar systems had already been reported in the past [1, $2,3]$, but only for water vapour measurements and not for temperature measurements. So this study is a first attempt in trying to fill this intercomparison gap.

\section{METHODOLOGY}

The Raman lidar system BASIL has been described in detail in a variety of previous papers (among others, $[4,5,6]$ ). During HyMeX-SOP 1 , BASIL was calibrated based on the comparison with radiosondes launched directly from the lidar site in Candillargues (approx. 100-150 m away).

In order to carry out an appropriate error analysis for the different sensors involved in the intercomparison effort, the mutual BIAS and rootmean-square (RMS) deviation of simultaneous and co-located data from the different sensors' pairs have been calculated. Expressions to compute these quantities have been reported by several authors $[1,2,3]$. Specifically:

$$
\begin{gathered}
B I A S=\frac{1}{N} \sum_{i=1}^{N} B I A S_{i}=\frac{2}{N} \sum_{i=1}^{N}\left\{\frac{\sum_{z=z_{1}}^{z_{2}}\left[q_{1}(z)-q_{2}(z)\right]}{\sum_{z=z_{1}}^{z_{2}}\left[q_{1}(z)+q_{2}(z)\right]}\right\} \\
R M S=\frac{1}{N} \sum_{i=1}^{N} R M S_{i}=\frac{2}{N} \sum_{i=1}^{N}\left\{\frac{\sqrt{N_{z} \sum_{z=z_{1}}^{z_{2}}\left[q_{1}(z)-q_{2}(z)\right]}}{\sum_{z=z_{1}}^{z_{2}}\left[q_{1}(z)+q_{2}(z)\right]}\right\}
\end{gathered}
$$

where $\mathrm{q}_{1}(\mathrm{z})$ and $\mathrm{q}_{2}(\mathrm{z})$ represent the water vapor mixing ratio values at altitude $\mathrm{z}$ for sensor 1 and sensor 2 , respectively, $z_{1}$ and $z_{2}$ are the lower and upper altitude of the considered altitude interval, respectively, and $\mathrm{Nz}$ is the number of data points for each sensor in this interval. In the present work, our attention was focused on altitude region $0.5-5.5 \mathrm{~km}$, with an interval width of $0.5 \mathrm{~km}$. Index $\mathrm{i}$, with values from 1 to $\mathrm{N}$, denotes the intercomparison sample, with $\mathrm{N}$ being the total number of possible comparisons for each pair of sensors. To apply expressions (1) and (2) a common altitude array has to be considered for each pair of sensors. Expressions (1) allow to compute relative BIAS and RMS deviation. Absolute BIAS and RMS deviation are obtained from expressions (1) and (2) by multiplying these expressions by the mean of the two sensors' data:

$$
2 \sum_{z=z_{1}}^{z_{2}}\left\{q_{1}(z)+q_{2}(z)\right\} / N_{z}
$$

\section{RESULTS}

Comparisons reported in this paper were carried out in the time period from 11 Sept. to 5 Nov. 2012. As an example of BASIL measurement capabilities, figure 1 illustrates the time evolution of temperature over a $3,3 \mathrm{~h}$ time interval from 
00:00 to 3:30 UTC on 30 October 2012. The figure is generated using a succession of 44 consecutive profiles (integration time $\Delta \mathrm{t}=5 \mathrm{~min}$, vertical resolution $\Delta \mathrm{z}=120 \mathrm{~m}$ ).

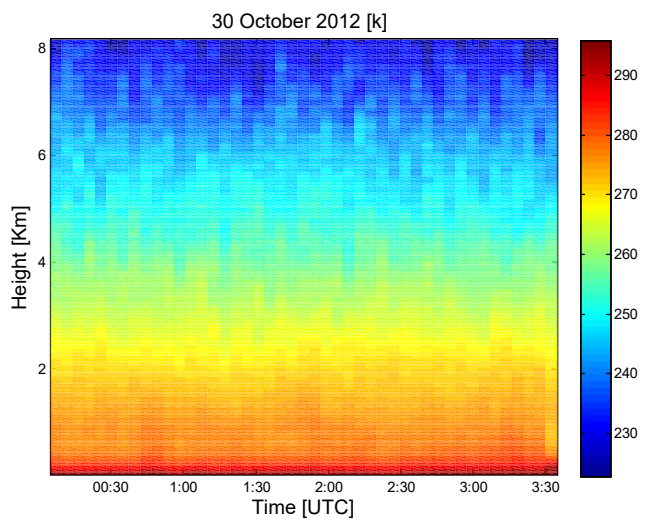

Figure 1 Time evolution of temperature from 00:00 UTC to 3:30 UTC on 30 October 2012.

A specific intercomparison effort was carried between BASIL and the airborne in-situ temperature sensor (a platinum resistance wire sensor). In-situ temperature measurements from measurements are usually collected during the aircraft take-off and landing phases.

On 12 September and 2 October 2012 the aircraft preformed specific ascending and descending loops in the proximity of the lidar site. Figure 2 illustrate the intercomparison between BASIL and the temperature in-situ sensor (hereafter represented with the short name IS). An integration time of $5 \mathrm{~min}$ has been considered for BASIL data.

The figure reveals a quite good agreement between these two sensors BASIL and the aircraft in situ sensors, obtained with a, is, with few specific exceptions. Specifically, absolute BIAS does not exceed $2 \mathrm{~K}$ in the free troposphere.

The higher BIAS values in the lowest $2 \mathrm{~km}$ are most probably associated with the temperature variability in the planetary boundary layer (it is to be kept in mind that the typical distance between the profiles' pairs is $20-30 \mathrm{~km}$ ) and with the systematic error affecting Raman lidar temperature measurements in the overlap region (in the lowest $1 \mathrm{~km}$ ).

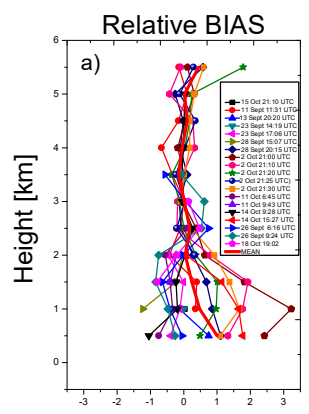

[\%]

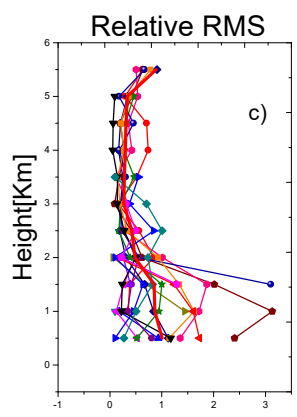

[\%]

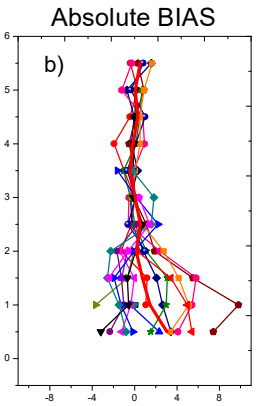

$[\mathrm{K}]$

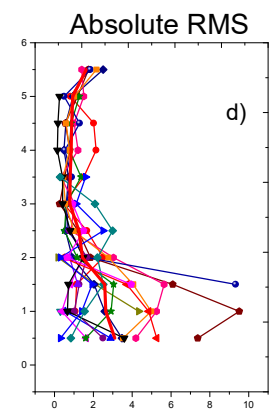

[K]
Figure 2 Relative (a) and absolute (b) BIAS and relative(c) and absolute(d) RMS deviation of BASIL vs. IS. Considered case studies are from period 11 September - 18 October 2012.

Figure 3 illustrates the vertical profiles of mean BIAS and RMS deviation for the different sensors' pairs. The figure reveals that the BIAS between BASIL and the radiosonde does not exceed $1.2 \mathrm{~K}$ or $0.75 \%$ above the planetary boundary layer, while the BIAS between BASIL and IS does not exceed $0.5 \mathrm{~K}$ or $0.25 \%$ above the planetary boundary layer. Again, deviations observed in the lower portion of the boundary layer are primarily due to the differences between the air masses sounded by the two sensors. This is also testified by the large values of RMS deviations in this same altitude range. Comparisons between BASIL and the microwave radiometer (MWR) were possible in the period 11 October-05 November 2012 (the MWR was deployed at a distance of 150-200 $\mathrm{m}$ from BASIL). During this period 348 night-time clear sky occurrences were identified and considered. The mean absolute BIAS and RMS deviation within the planetary boundary layer are found to have values not exceeding $1 \mathrm{~K}$ and $2 \mathrm{~K}$, respectively. 

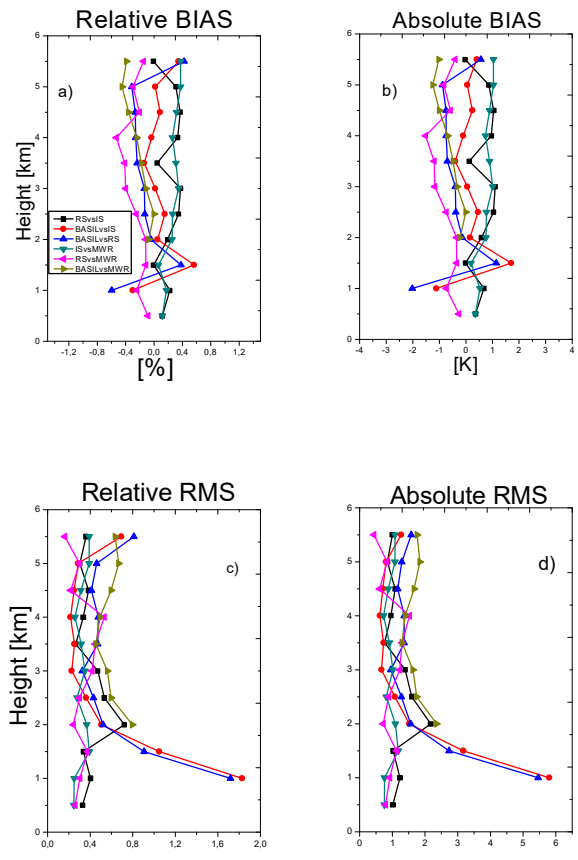

$[\mathrm{K}]$

Figure 3 Average values of Relative BIAS, absolute Bias, relative RMS and absolute RMS deviation for all sensors

Vertically averaged values of BIAS and RMS deviation for all sensors' pairs are listed in Table1. The mean absolute BIAS of BASIL vs. RS -is $0.25 \mathrm{~K}$, while the mean absolute BIAS of BASIL vs. MWR and IS are $0.74 \mathrm{~K}$ and $0.28 \mathrm{~K}$, respectively. The mean absolute BIAS of RS vs. MWR and IS are $-0.74 \mathrm{~K}$ and $0.610 \mathrm{~K}$, respectively. Finally, the mean absolute BIAS of MWR vs. IS is $0.74 \mathrm{~K}$. More results from this study will be illustrated at the Conference.

Table 1 Intercomparison between all sensor's pairs

\begin{tabular}{|c|c|c|c|c|}
\hline & $\begin{array}{c}\text { BIAS } \\
{[\%]}\end{array}$ & $\begin{array}{c}\text { BIAS } \\
{[\mathrm{K}]}\end{array}$ & $\begin{array}{c}\text { RMS } \\
{[\%]}\end{array}$ & $\begin{array}{c}\text { RMS } \\
{[\mathrm{K}]}\end{array}$ \\
\hline RS vs. IS & 0,20 & 0,61 & 0,40 & 1,19 \\
\hline BASIL vs. IS & 0,12 & 0,28 & 0,43 & 1,17 \\
\hline BASIL vs. RS & $-0,06$ & $-0,25$ & 0,53 & 1,48 \\
\hline IS vs. MWR & 0,26 & 0,74 & 0,32 & 0,94 \\
\hline RS vs. MWR & $-0,25$ & $-0,74$ & 0,32 & 0,94 \\
\hline BASIL vs.MWR & $-0,23$ & $-0,62$ & 0,60 & 1,71 \\
\hline
\end{tabular}

\section{References}

[1] Whiteman, D.N., Demoz, B.B., Di Girolamo, P., Come,r J., Veselovskii, I., Evans, K., Wang,

Z., Sabatino, D., Schwemmer, G., Gentry, B., Lin, R.-F., Behrendt, A., Wulfmeyer, V., Browell, E., Ferrare, R., Ismail, S.,Wang,J., 2006. Raman lidar measurements during the International H2O Project. Part II: Case studies. J. Atmos. Oceanic Technol., 23, 170-183.

[2] Behrendt, A., Wulfmeye,r V., Di Girolamo, P., Kiemle, C., Bauer, H.-S., Schaberl, T., Summa, D., Whiteman, D.N., Demoz, B.B., Browell, E.V., Ismail, S., Ferrare, R., Kooi, S., Ehret, G, Wang, J., 2007a. Intercomparison of water vapor data measured with lidar during IHOP 2002. Part I: Airborne to ground-based lidar systems and comparisons with chilled-mirror hygrometer radiosondes. J. Atmos. Oceanic Technol.,24, 3-21.

[3] Bhawar, R.,Di Girolamo,P., Summa,D., Flamant, C., Althausen, D., Behrendt, A., Kiemle, C., Bosser, P., Cacciani, M., Champollion, C., Di Iorio, T., Engelmann, R., Herold, C., Müller, D., Pal,S., Wirth, M., Wulfmeyer, V., 2011: The Water Vapour Intercomparison Effort in the Framework of the Convective and Orographically-Induced Precipitation Study: Airborne-to-Ground-based and airborne-to-airborne Lidar Systems, Quarterly Journal of the Royal Meterological Society, 137, 325-348.

[4] Di Girolamo, P., Summa, D., Ferretti, R.: Multiparameter Raman Lidar Measurements for the Characterization of a Dry Stratospheric Intrusion Event. J. Atm. Ocean. Tech.., 26, 1742-1762, doi:10.1175/2009JTECHA1253.1, 2009 a.

[5] Di Girolamo, P., Flamant, C., Cacciani, M., Richard, E., Ducrocq, V., Summa, D., Stelitano, D., Fourrié, N., and Saïd, F., (2016), Observation of low-level wind reversals in the Gulf of Lion area and their impact on the water vapour variability, Quarterly Journal of the Royal Meterological Society., 142 (Suppl 1), 153-172, doi:10.1002/qj.2767.

[6] Di Girolamo, P., Cacciani, M., Summa,D., Scoccione, A., De Rosa, B., Beherendt A., and Wulfmeyer, V., (2017), Characterisation of boundary layer turbulent processes by the Raman lidar BASIL in the frame of HD(CP) 2 Observational Prototype Experiment, Atmos. Chem.Phys.,17, 745-767, doi:10.5194/acp-17745-2017. 